\title{
Is coagulopathy a common consequence of a Vipera berus bite? A retrospective single centre study
}

\author{
Katarzyna Elżbieta Dyląg-Trojanowska ${ }^{1, A-F}$, Diana Hodorowicz-Zaniewska ${ }^{2, A, D, F}$, \\ Justyna Zybaczyńska3,D-F, Antoni M. Szczepanik ${ }^{2, A, C-E}$ \\ ${ }^{1}$ Department of General Surgery John Gawlik Hospital, Sucha Beskidzka, Poland \\ ${ }^{2}$ First Department of General, Oncological \& Gastroenterological Surgery Jagiellonian University Medical College, Cracow, Poland \\ 3 Jagiellonian University Medical College, Cracow, Poland \\ A - Research concept and design, B - Collection and/or assembly of data, C - Data analysis and interpretation, \\ $D$ - Writing the article, E - Critical revision of the article, F - Final approval of article
}

Dyląg-Trojanowska KE, Hodorowicz-Zaniewska D, Zybaczyńska J, Szczepanik AM. Is coagulopathy a common consequence of a Vipera berus bite? A retrospective single centre study. Ann Agric Env Med. 2018; 25(4): 630-634. doi: 10.26444/aaem/75941

\begin{abstract}
Introduction. The Vipera berus (common viper) is the only species of venomous snake found in Poland. The aim of this study was to determine to what extent coagulopathy has occurred as a post-bite complication.

Materials and method. The medical records of 138 adult patients in the Sucha Beskidzka hospital with the diagnosis of snake bite between 2001-2014 were retrospectively analyzed. Demographic, clinical and laboratory data were collected. Antivenom was given to all patients, except one, with snake bites, but laboratory test were taken prior to administration of antivenom. Obtained results were compared to those of the control group, composed of 176 adults hospitalized in the same period for an elective laparoscopic cholecystectomy.

Results. The mean platelet count in the study group was $239.94 \times 109 / \mathrm{L}(\mathrm{SD}=56.56)$ and $248.77 \times 109 / \mathrm{L}(\mathrm{SD}=57.82)$ in the control group. In $98 \%$ of the study group and $100 \%$ of the control group the platelet value (PLT) fell within laboratory norms ( 130 to $420 \times 109 / \mathrm{L}), 2$ patients after snake bites had a PLT lower than normal, and thrombocytosis was not observed in either group. A reference range of 0.85-1.3 INR below normal was found in 2 patients in the study group and 15 from the control group, while values above the normal range were found in 8 patients (6.7\%) from the snake bite group and no patients from the control group. In the study group, the INR ranged from 0.78-1.43 with a mean of 1.046 (SD=0.14), while in the control group the range was from $0.79-1.28$, with a mean of $0.95(S D=0.08)$. There was a significant difference in INR between the study and control groups $(p<0.0001)$.

Conclusions. The bite from V. berus does not result in severe thrombocytopenia, with only a moderate increase in INR values observed in about $7 \%$ of patients.
\end{abstract}

Key words

Poland, thrombocytopenia, coagulopathy, venom, antivenom, envenomation, Vipera berus bite, snake, snakebite

\section{INTRODUCTION}

Venomous snakes compose about $20 \%$ of all snake species, and are most commonly found in regions such as Australia or Asia. The two most common snake families responsible for the highest burden of bites are the Viperidae and Elapidae families. Typically, elapidous snake bites lead to neurotoxicity [1] and viperous bites to coagulopathy, which is one of the most common systemic complications and cause of death amongst venomous animals worldwide [2]. The only venomous snake found in Poland is the Vipera berus L.1758, commonly known as the viper snake $[3,4]$. According to recent information from the Polish Ministry of the Environment there is no data about the size of Vipera berus population in Poland [5]. On the other hand, in some habitats up to 59 snakes per hectare have been recorded [6].

To describe the various types of blood clotting disorders arising from bites, the term "venom-induced consumption coagulopathy" (VICC) has been introduced. VICC occurs

Address for correspondence: Katarzyna Elżbieta Dylag-Trojanowska, Department of General Surgery John Gawlik Hospital, Sucha Beskidzka, Poland e-mail: kadgta@interia.pl

Received: 18.05.2017; accepted: 18.07.2017; first published: 16.10.2017 following bites from a variety of snakes, including, but not limited to, Viperid and Elapid snakes. Snake venom contains procoagulant toxins, such as factor $\mathrm{V}, \mathrm{X}$, and prothrombin activators, fibrinogenases and thrombin-like enzymes (TLE). Some of these are more potent than others, and the severity and duration of symptoms varies between toxins. Factor activators lead to factor depletion and deficiencies, while TLE's and fibrinogenases cleave fibrinogen without forming fibrin, causing a low to undetectable blood fibrinogen concentration. Diagnosis of VICC is performed by measuring clotting times, most commonly prothrombin (PT), partial thromboplastin time (PTT), and the international normalized ratio (INR) $[7,8]$. VICC describes coagulopathies; however, it is not synonymous with disseminated intravascular coagulation (DIC). Hallmark features of DIC, such as systemic microthrombi and end organ failure, are not present is VICC [2]. Viperid and elapid snake bites are also observed to elicit complications consistent with thrombotic microangiopathy, with development of acute renal failure, thrombocytopenia, and microangiopathic haemolytic anaemia [7]. Mortality post-VICC is dependent on many factors, including platelet count, function, trauma and presence of vascular injury. Vessel damage may lead to haemorrhages through the release 
of tissue factor. Bleeding severity has a wide range, from local bleeding to life- threatening intracranial or multi-organ haemorrhaging. [8].

VICC diagnosis is usually a combination of patient history which includes the snake bite and blood test results indicating factor consumption coagulopathy. Blood test findings can include abnormal INR or PT, low fibrinogen or elevated D-Dimer levels. Fibrinogen is the most commonly consumed clotting factor in snake bites [8]. The above observations apply mainly to tropical snakes, including the viperous species. However, a recent study performed by Polish and Slovak researchers demonstrated that the venom of Vipera berus contains a full spectrum of haemotoxins [9]. These are thrombin like enzymes, serine proteases, activators of protein C, phospjholipases A2, C-type lectin like proteins and snake venom metalloproteinases.

In Central European countries, venomous snakes are represented only by V.berus. In the literature, coagulopathy is listed as one of the effects of V.berus; however, there is little data pertaining to the frequency of this complication in clinical practice.

The present study reports data from the hospital in Sucha Beskidzka, a town located in the north-western part of

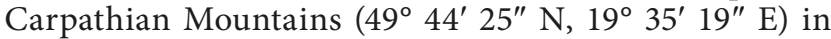
Poland, a region where the V.berus population is large. V.berus is the most common among all of venomous snakes found in Europe. This species can be found in a variety of habitats from grassy fields to rocky slopes, and on farms and cultivated lands [6].

\section{OBJECTIVE}

The aim of this study was to determine to what extent coagulopathy has occurred as a complication of V.berus bites among the patients from the hospital in Sucha Beskidzka, Poland.

\section{MATERIALS AND METHOD}

This was a retrospective cohort study performed between 2001-2014 among 138 adult patients with the diagnosis of snake bite. The number of cases per year ranged from 4-15, with the average of 9.85. In the same period, 42 children were admitted after a V.berus bite; however, children were excluded from the study because of the lack of an adequate control group. The events occurred between April and September, with the highest incidence in June and July. Data about the patients were collected retrospectively from medical documentation. It included information on demographics age, gender (Tab. 1), history, month of hospitalization, length of hospital stay, site of bite, local and systemic symptoms of envenomation, intensity of symptoms, and blood test results.

Table 1. Demography of patients

\begin{tabular}{lccc}
\hline Age groups (years) & $<18$ & $18-65$ & $>65$ \\
\hline Gender & & & \\
\hline Males & 24 & 61 & 10 \\
\hline Females & 18 & 51 & 16 \\
\hline Total & $\mathbf{4 2}$ & $\mathbf{1 1 2}$ & $\mathbf{2 6}$ \\
\hline
\end{tabular}

The intensity of symptoms was rated on a 4-degree scale: grade 0 (G0) - 'dry' bite without signs of envenomation, with the presence of teeth marks; grade 1 (G1) - mild poisoning, with limited local symptoms, reaching its peak after 24-48 hours; grade 2 (G2) - average poisoning with regional oedema on affected limb and mild systemic symptoms (mild nausea, abdominal pain, diarrhea, slight changes in arterial blood pressure, tachycardia, hypotonia); grade 3 (G3) - severe poisoning with diffuse oedema spreading to the abdomen, life-threatening systemic symptoms (significant or prolonged hypotonia, haemorrhagic shock) [10]. Blood tests were carried out within 1-4 hours after patient admission to hospital, but prior to the administration of antivenom. In the control group, blood tests were carried out on the day of admission. For the assessment of blood clotting, the International Normalized Ratio (INR) and platelet count (PLT) were measured. The local laboratory norm for INR is between $0.85-1.3$, while the laboratory norm for PLT is between $130-420 \times 10^{9} / \mathrm{L}$. None of the patients used anticoagulant medications prior to admission. All the patients (except one who refused) with snake bites received antivenom serum (Immunoserum contra venena viperarum europaearum, BIOMED, Warsaw, Poland), at the dose of 500 antitoxic U im. A group of 138 patients (70 women and 68 men) was qualified for the study, with ages ranging from 18 to 90 years; mean age -49 . In this group, platelet counts at admission were measured in 127 patients, and INR at admission in 119. Both parameters were measured in 118 patients, platelet count only in 9 patients and INR only in one patient. In 10 patients, only clinical assessment without blood tests on admission was performed. This occurred because blood tests were at the discretion of the consulting physician. Routine physical examinations were performed in all 138 patients, including assessment of the signs of impaired coagulation (bleeding, bruises, ecchymoses, thrombosis, etc.). Obtained results were compared with a control group of adults admitted for an elective laparoscopic cholecystectomy. These patients were from the same geographic region as the study group, and their hospitalizations occurred in the same months as those of the viper bite patients. The control group was composed of 176 patients ( 90 women and 86 men); mean age - 52 years. Statistical analysis on PLT and INR mean values between the study and the control groups was performed (comparison of means statistics), and significance accepted at $\mathrm{p}<0.05$.

\section{RESULTS}

In 70 cases, snake bites affected the upper extremity, in 67 the lower extremity and in one case, the trunk. Among all patients, 72 presented with Grade 2 symptoms (52\%), 50 with G1 (36\%), 11 with G0 (8\%), and only 5 with G3 (4\%) severity of symptoms (Tab.2).

Table 2. Severity of poisoning in study group

\begin{tabular}{lcccc}
\hline Severity of poisoning in study group & G0 & G1 & G2 & G3 \\
\hline No. of patients & 11 & 50 & 72 & 5 \\
\hline$\%$ of patients (\%) & 8 & 36.2 & 52.2 & 3.6 \\
\hline
\end{tabular}

No clinical symptoms of coagulopathy were observed. Local symptoms of haematoma were found in 59 patients (43\%), while oedema was observed in 123 cases (89\%). No 
Table 3. Results in study and control group

\begin{tabular}{lcccccccccccccccccccc}
\hline \multicolumn{1}{c}{ Control group } \\
\hline Parameter & mean & SD & median & $\min$ & $\max$ & IQR & mean & SD & median & min & max & IQR & P-value \\
\hline PLT & 239.9 & 56.56 & 237 & 113 & 396 & 85 & 248.7 & 57.82 & 242.2 & 133.2 & 402.1 & 68 & 0.2844 \\
\hline INR & 1.046 & 0.1368 & 1.030 & 0.78 & 1.430 & 0.19 & 0.95 & 0.08 & 0.95 & 0.79 & 1.280 & 0.11 & $<0.0001$ \\
\hline
\end{tabular}

thromboembolic complications were recorded. In 17 patients, low molecular weight heparin (LMWH) was administered due to marked oedema of the lower extremity. No sideeffects of antivenom administration were observed. In the 10 patients who had no blood tests within 1-4 hours after admission to the hospital, 2 were assessed as G0, 3 as G1, and 4 as G2, 1 as G3.

Table 3 shows the results of measured and calculated parameters in the study and control groups.

The mean platelet count in the study group was $239.94 \times 10^{9} / \mathrm{L}$ $(\mathrm{SD}=56.56)$ which was lower than that of the control group $248.77 \times 10^{9} / \mathrm{L}(\mathrm{SD}=57.82)$. This difference did not reach statistical significance. In $98 \%$ of the study group and $100 \%$ of the control group the platelet value fell within laboratory norms. Only 2 patients after snake bites had a platelet value lower than normal. Thrombocytosis was not observed in either group (Fig.1a).

For further analysis, the study group was divided into 2 subgroups according to the intensity of symptoms: $\mathrm{G} 0+\mathrm{G} 1(\mathrm{n}=56)$ and $\mathrm{G} 2+\mathrm{G} 3(\mathrm{n}=71)$. The mean platelet count were $249 \times 10^{9} / \mathrm{L}(\mathrm{SD}=55.39)$ and $232.8 \times 10^{9} / \mathrm{L}(\mathrm{SD}=56.84)$, respectively. There was no statistically significant difference between the G0+G1 and G2+G3 subgroups in PLT count distribution (Fig. 1b).

The distribution of INR was as follows: INR below normal $(\mathrm{N}: 0.85-1.3)$ was found in 2 patients in the study group and 15 patients from the control group, while values above the normal range were found in 8 patients $(6.7 \%)$ from the snake bite group and no patients from the control group. In the study group, the INR ranged from $0.78-1.43$, and in the control group, the range was from $0.79-1.28$. (Fig. 2a).

Mean INR in the study group was $1.046(\mathrm{SD}=0.14)$, which was higher than the mean in the control group -0.95 $(\mathrm{SD}=0.08)$. Statistical analysis showed a significant difference between INR in study and control groups ( $p<0.0001 ; 95 \%$ CI -0.1209 to -0.0711 ).

Analysis in the G0+G1 and G2+G3 subgroups showed that the mean INR was $1.06(\mathrm{SD}=0.13)$ and $1.03(\mathrm{SD}=0.15)$, respectively. There was no statistical difference between subgroups in mean count, nor in the distribution of results (Fig. 2b).

\section{DISCUSSION}

This study was carried out in a single centre, a regional hospital in southern Poland located close to the known habitats of the $V$. berus. It analyses one of the largest data collections from a single centre, whereas other larger studies have been rather nationwide studies $[11,12,13]$. The data were collected during 14 years and based upon clinical records. No extensive
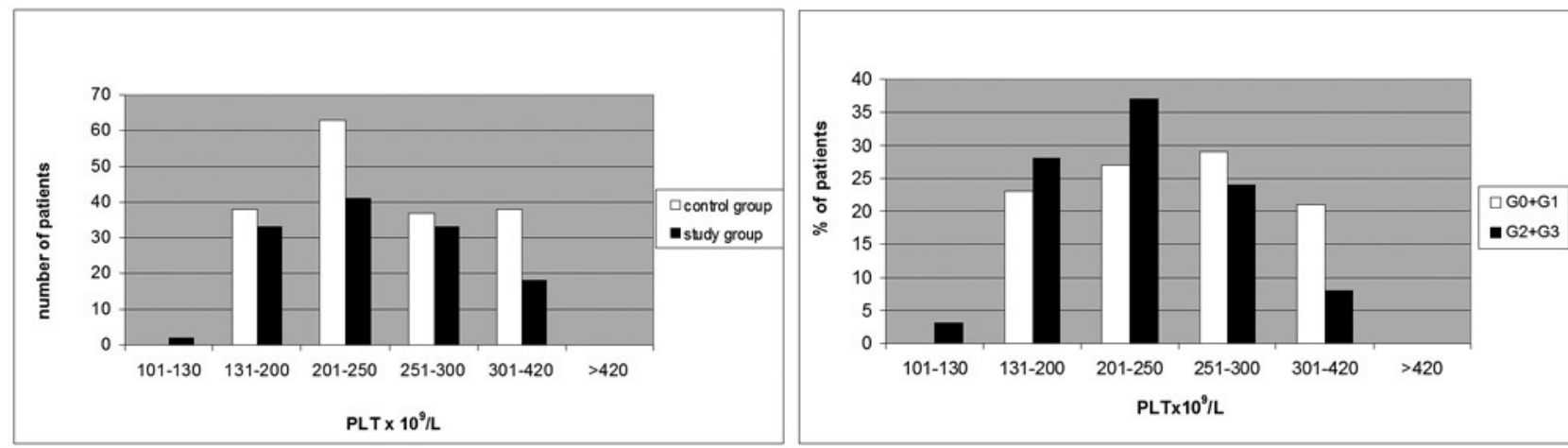

Figure 1a and 1b. Comparison of platelet count between study and control groups [1a] and Distribution of platelet count in G0+G1 and G2+G3 subgroups [1b]
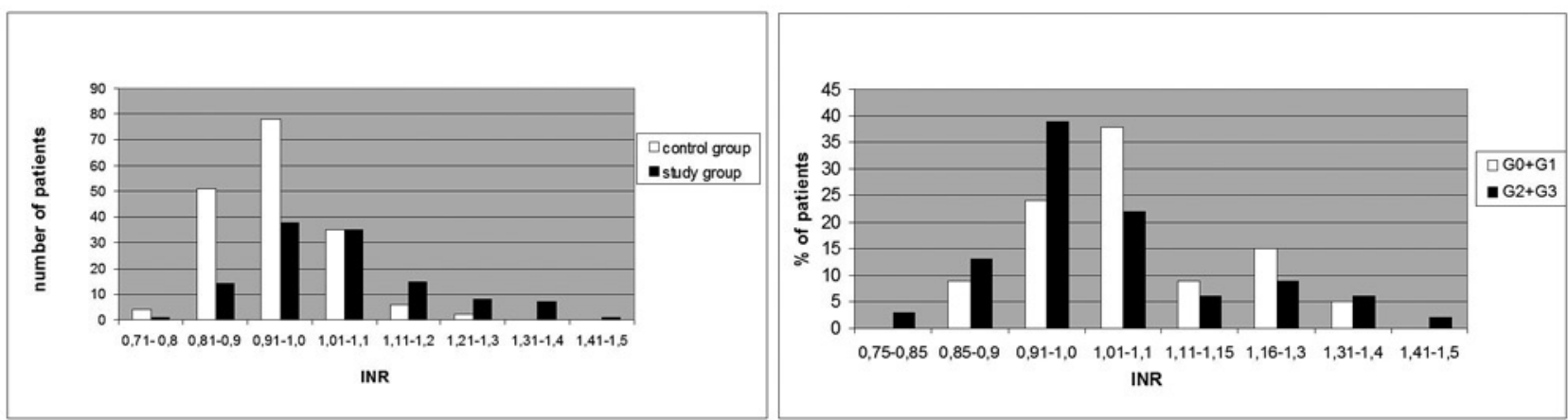

Figure 2a and $\mathbf{2 b}$. Comparison of INR values between study and control groups [2a] and Distribution of INR values in G0+G1 and G2+G3 subgroups [2b] 
laboratory tests were used. The majority of patients had their INR and PLT values measured on admission. There are some literature data which states that in patients after a bite by the common viper, measurements of fibrinogen levels may be useful [7]. However, this parameter was not assessed in the current study, since none of the patients had clinical signs of VICC and there were no indications for detailed blood clotting tests. Blood clotting disorders are reported as one of the consequences of $V$. berus bite; however, they are probably not common $[8,10]$. No report was found in the literature which focused on this subject. The presented group is large enough to detect adverse effects which occur in less than 5 $-10 \%$ of patients. There are multiple factors in the venom of the $V$. berus which may interfere with the coagulation system. The effects of phospholipase A2 through the activation of the inflammatory cascade may impair platelet function, and probably lead to platelet lysis. Thrombocytopenia has been reported as an important consequence and prognostic factor in patients after a bite from exotic snakes from India [14]. The case of a patient with severe thrombocytopenia after a bite from the Vipera ammodytes ammodytes in Bulgaria was also reported [15]. In the presented group of 127 patients with PLT count measured, only 2 patients were below normal count. However, in both cases the PLT count was above $100 \times 10^{9} / \mathrm{L}$. In the study group, PLT count did not differ significantly from the control group. There was also no difference between PLT count in patients with minimal symptoms of envenomation $(\mathrm{G} 0+\mathrm{G} 1)$ and those with more intense symptoms (G2+G3). This may suggest that the venom of $V$. berus does not lead to severe thrombocytopenia. In a different study from Poland, only one case of mild thrombocytopenia has been reported [16]. Another Polish study reported thrombocytopenia below $50 \times 10^{9} / \mathrm{L}$ in 6 of 26 patients, which is contrary to findings in the presented study [17].

Analysis of INR results in 119 patients revealed a few cases with values slightly different from the normal range: INR was lower in 2 patients, while in 8 patients it was higher than normal. The differences in INR values between study and control groups were significant; however, there was no association of INR with intensity of local symptoms. The venom of $V$. berus may influence INR through altered activity of coagulation factor $\mathrm{V}[10,15]$. The effects may vary from hypercoagulation to hypocoagulation depending on the amount of venom $[1,10]$. The presented results, however, do not support this observation. In a group of 15 patients from north-eastern Poland, INR was increased in only one case, which is in line with this study [16]. A nationwide French study [12] also did not reported serious hypocoagulation in patients after a $V$. berus bite. A case of pulmonary embolism in one $V$. berus bite patient has been reported by other French authors [18]. Such complications were not observed in either the current study nor the large study performed in France [12]. In a group of 17 patients from the current study, LMWH was administered as prophylaxis in patients with marked oedema of the lower extremity. This indication has also been reported by others $[12,17]$.

All except one snake bite patient received antivenom serum, regardless of the intensity of their symptoms. This may be assessed as an over-treatment; however, the administration of serum could not influence the results of initial blood tests because the blood tests were performed prior to administration of the antivenom, therefore the treatment could not influence the blood test results.
Antivenom binds the toxins and can potentially block the active site of a toxin. Additionally, the complexes (antivenom toxins) can be eliminated from circulation. On the other hand, irreversible toxic effects cannot be reversed by antivenom binding to toxins after damage such as clotting factor deficiencies has occurred [19]. The antivenom may be effective if administered early, before the impairment of clotting factors occurrs [20].

In the presented study, antivenom was administered early to the patients due to the proximity of the hospital to the place of the snake bite incidents. However, there was verified data available about the time between the bite and antivenom administration. Although this is the weakness of the study, in a retrospective study the authors were unable to obtain this information and it is therefore impossible to prove with the obtained results whether or not the administration of the antivenom had a beneficial effect.

This study demonstrates that the bite from $V$. berus does not result in severe thrombocytopenia, with only a moderate increase in INR values observed in about $7 \%$ of patients. Therefore, extensive blood clotting tests are probably justified only in severely intoxicated patients or in patients with a specific medical history.

\section{REFERENCES}

1. Gutiérrez JM, Williams D, Fan HW, Warrell DA. Snakebite envenoming from a global perspective: Towards an integrated approach. Toxicon. 2010; 56(7): 1223-1235.

2. Isbister GK. Snakebite doesn't cause disseminated intravascular coagulation: coagulopathy and thrombotic microangiopathy in snake envenoming Semin Thromb Hemost. 2010; 36(4): 444-451.

3. Ciszowski K, Modła A. [Envenoming by common viper (V. berus) subject still exists...]. Przegl Lek. 2004; 61(4): 427-432. Polish

4. Wierzbicka I, Prokopowicz D, Kołakowska R, Panasiuk A. [Snake bites]. Przegl Epidemiol. 1997; 51(3): 359-362. Polish

5. Ostapiuk J. Odpowiedź podsekretarza stanu w Ministerstwie Środowiska - z upoważnienia ministra - na interpelację nr 26993 w sprawie udzielenia odszkodowań za zwierzęta hodowlane śmiertelnie ukąszone przez żmije. http://www.sejm.gov.pl/Sejm7.nsf/ InterpelacjaTresc.xsp?key=121E86D9 (access 2017.07.05)

6. Kośmider J, Nawrocka M, Jobda M, Jasińska K. [Variable habitat preferences of the common European adder Vipera berus observed in the provinces of Mazovia and Lublin (Poland)]. Studia i Materiały CEPL w Rogowie 2013; 36(3):184-194 http://cepl.sggw.pl/sim/pdf/sim36_pdf/ Kosmider.pdf (access 2017.07.05)

7. Kalana M, Isbister GK. Current Treatment for Venom - Induced Consumption Coagulopathy Resulting from Snakebite. PLoS Negl Trop Dis 2014; 8(10): e3220.

8. Berling I, Isbister GK. Hematologic Effects And Complications Of Snake Envenoming. Transfus Medi Rev. 2015; 29(2): 82-89.

9. Bocian A, Urbanik M, Hus K, Łyskowski A, Petrilla V, Andrejcakova Z, et al. Proteome and Peptidome of Vipera berus berus Venom. Molecules 2016; 21:1398. doi:10.3390/molecules21101398

10. Czajka U, Wiatrzyk A, Lutyńska A. [Mechanism of Vipera berus venom activity and the principles of antivenom administration in treatment]. Przegl Epidemiol. 2013; 67(4): 729 -733. Polish

11. Karlson-Stiber Ch, Salmonson H, Persson H. A nationwide Study of Vipera Berus Bites during one Year - epidemiology and morbidity of 231 cases. Clin Toxicol. 2006; 44(1): 25-30.

12. Jollivet V, Hamel JF, de Haro L, Labadie M, Sapori JM, Cordier L, et al. European viper envenomation recorded by French poison control centers: A clinical assessment and management study. Toxicon. 2015; 108: 97-103.

13. Grönlund J, Vuori A, Nieminen S. Adder bites. A report of 68 cases. Scand J Surg. 2003; 92(2): 171-174.

14. Menon JC, Joseph JK, Jose MP, Dhananjaya BL, Oommen OV. Clinical Profile and Laboratory Parameters in 1051 Victims of Snakebite from a Single Centre in Kerala, South India. J Assoc Physicians India. 2016; 64(8): 22-29. 
15. Marinov I, Atanasov VN, Stankova E, Duhalov D, Petrova S, Hubenova A. Severe coagulopathy after Vipera ammodytes ammodytes snakebite in Bulgaria: a case report. Toxicon. 2010; 56(6):1066-1069.

16. Garkowski A, Czupryna P, Zajkowska A, Pancewicz S, Moniuszko A, Kondrusik M, et al. Vipera berus bites in Eastern Poland - a retrospective analysis of 15 case studies. Ann Agric Environ Med. 2012; 19(4): 793-797.

17. Magdalan J, Trocha M, Merwid-Lad A, Sozański T, Zawadzki M. Vipera berus bites in the Region of Southwest Poland - a clinical analysis of 26 cases. Wilderness Environ Med. 2010; 21(2): 114-119.
18. Bart G, Pineau S, Biron C, Connault J, Artifoni M. Bilateral Pulmonary Embolism Following a Viper Envenomation in France: A Case Report and Review. Medicine (Baltimore). 2016; 95(19): e2798.

19. Isbister GK, Duffull SB, Brown SG. Failure of antivenom to improve recovery in Australian snakebite coagulopathy. QJM. 2009; 102: 563-568.

20. Boels D, Hamel JF, Bretaudeau Deguigne M, Harry P. European viper envenomings: Assessment of Viperfav ${ }^{\mathrm{Ts}}$ and other symptomatic treatments. Clin Toxicol (Phila). 2012; 50(3): 1891-96. 